\title{
Big Data Signaling in Annual Reports: Does the Presence of a Chief Data Officer (CDO) Signal Big Data Initiatives in Annual Financial Reports?
}

\section{Lisa Kralina*}

Anderson University, Anderson, Indiana, USA

\begin{abstract}
Big data is here to stay. The results of this empirical study suggest that the presence of a Chief Data Officer (CDO) signals big data initiatives in annual financial reports. 150 annual reports of top Fortune 500 (F500) companies and top Fortune Fastest Growing (FFG) companies are examined by content analysis using eighteen predetermined keywords. CDOs are executive leaders in $64 \%$ of companies. FFG companies with CDOs use $58 \%$ more keywords than non-CDO FFGs, while F500 companies with CDOs use $12 \%$ more keywords than non-CDO F500s. Results by industry are compared. Three Ps (prominence, prioritization, partnership) are discussed. Increasing prominence of big data initiatives and data-based decision-making and prioritization of building analytical capabilities reinforce the need for Chief Financial Officer (CFO) and CDO partnerships. This study suggests that tech-savvy finance teams with data expertise gain competitive advantages. Further studies are needed to scrutinize financial decision-making implications, dissect roles and accountability and extrapolate industry distinctions.
\end{abstract}

Keywords: Big data; Signaling; Annual reports; Chief financial officer (CFO); Chief data officer (CDO)

\section{Introduction}

The use of big data has been categorized as a paradigm shift at the scale of the Industrial Revolution [1]. Big data can be defined as large, diverse, complex, and/or longitudinal data sets generated from a variety of instruments, sensors, and/or computer-based transactions [2]. Big data comes in all shapes and sizes and does not fit into prior financial models. It constantly changes, often invalidating any interpretable patterns [3]. "Data is the lifeblood of every industry working to reinvent itself in the modern age. Companies that use data will thrive and grow; companies that don't will fall behind" claims Intel's shareholder letter [4].

However, strategists differ in the role of big data. A founding father of corporate strategy, Ansoff [5] warns that managers need all the 'computer help' they can get. Big data continues to become more accessible and offers more analytical opportunities. As predicted, businesses are rapidly digitizing and accumulating abundant data to predict needs, avert fraud, and build relationships [3]. Companies are extensively investing in new data resources, such as CDOs, data storage tools and innovation labs [6]. Constantiou and Kallinikos [7] assert that big data erodes the basis of decision-making models. Old-school strategic decision-making hinged on minimizing costs or differentiating products [8]. Mazzei and Noble [9] find that corporate strategy no longer dictates which data should be collected; conversely, data collected and analyzed may now influence corporate strategy. Brynjolfsson et al. [10] find that firms making data-driven decisions result in 5-6\% higher productivity. It is the process, not individual pieces of data, that derive value.

Firms are deriving value through big data and business analytics [11]. This new value is reflected in annual reports, a required and useful medium for public companies to convey information to shareholders. Company objectives must appeal to customers as well as constantly adapt to the changing values of customers [12]. These voluntary disclosures in corporate reporting [13], have their origins in information asymmetry of signaling theory [14]. Signaling theory suggests companies relay favorable news to attract investors and enhance their reputation [15].
This implies that company executives are incented to signal expected future value of big data and digital initiatives through annual reports and other shareholder communications.

While extant research focuses on technological tools and data storage techniques, this empirical study examines if the presence of a Chief Data Officer (CDO) signals big data initiatives in annual financial reports.

\section{Material and Methods}

Adhering to the research design outlined by Srnka and Koeszegi [16], this study uses content analysis to transform keywords into coded data for quantitative analyses. George et al. [17] suggest that business empirical research often infers relationships via unstructured textual form.

The sample includes 150 annual reports of 75 companies. The top 50 of the 2017 Fortune 500 (F500) list plus the top 25 of 2017 Fortune Fastest Growing (FFG) company list are captured [18]. The F500 list is ordered by highest total revenue, and the FFG list is ranked based on three criteria: revenue growth rate, earnings-per-share growth rate, and three-year annualized total return [19]. The sample includes 2012 and 2016 (or most current fiscal year) annual reports for all 75 companies. The year 2012 represents a time of substantial adoption of big data and digital initiatives [6]. Annual reports have been retrieved from company websites and assessed independently in September and October 2017.

Eighteen predefined keywords are selected based on recurrent

${ }^{*}$ Corresponding author: Lisa Kralina, Anderson University, 1100 Fifth Street, Anderson, Indiana, USA, Tel: 64654915; E-mail: Imkralina@anderson.edu

Received April 06, 2018; Accepted April 24, 2018; Published April 30, 2018

Citation: Kralina L (2018) Big Data Signaling in Annual Reports: Does the Presence of a Chief Data Officer (CDO) Signal Big Data Initiatives in Annual Financial Reports? J Bus Fin Aff 7: 331. doi: 10.4172/2167-0234.1000331

Copyright: (c) 2018 Kralina L. This is an open-access article distributed under the terms of the Creative Commons Attribution License, which permits unrestricted use, distribution, and reproduction in any medium, provided the original author and source are credited. 
words in extant big data theory and extracted from published company annual reports. The keywords are: big data, data, analyt\#, digital, disrupt, technolog\#, revolut\#, machine learn, cloud, cyber, internet, innovat\#, capabilit\#, competitive, advantage, transform, personaliz\# and customiz\#. A wildcard symbol (\#) captures variations of the word. For example, "personaliz\#" captures personalize, personalized, personalization and so forth.

A CDO is counted if the company publically lists this title or equivalent on the executive leadership team on its company website. Equivalent titles include Chief Information Officer, Chief Digital Officer, Chief Technology Officer and any EVP or SVP (executive or senior vice president) titles with those words. These named roles are represented as "CDO" for the remainder of this paper. Executives for a specific operational business unit (such as Head of Internet Business) are excluded.

Quality checks have been performed to ensure the results are valid and reliable. Of the original company listings, seven companies are removed due to unavailable public reports (three private companies), duplication (one on both lists) and inconsistent reporting (three nonUS companies); thus, the next seven companies are added. The revised 75 companies are disbursed over seven industries and 25 states. A review of the SEC website confirms credibility and consistency with reported financials. Relevance is established as all companies use at least 30 keywords per report.

\section{Results}

CDOs are employed as executive leaders at 48 of the 75 companies (64\%). CDOs are executive leaders at $72 \%$ of F500 companies and $48 \%$ of FFG companies. Comparing industries, consumer-related has the highest percentage (82\%). Healthcare, industrial and telecom rank lowest (50\%). A CFO is listed as an executive leader at all 75 companies.

The average number of keywords per report is 168 in 2012 and 192 in 2016, a 14\% growth. In 2016, F500 averages 203 keywords (20\% more than FFG) but also publishes 40 more pages per report $(30 \%$ higher) than FFG. The technology industry has the highest average of 367 keywords while energy has the lowest average of 93 keywords in 2016. The companies with the highest volume of keywords (over 400 each) are IBM, GE, JPMC, Dell Tech, and Arista.

Notably, the phrase "big data" is rarely used (45 total instances) and decreases by $39 \%$ from 2012 to 2016 . Keywords showing the highest increase in frequency between 2012 and 2016 are 'digital', 'cloud' and 'cyber'. The keyword "machine learning" has the highest percentage increase (543\%); yet, this keyword is only found in the technology and financial industries.

In terms of executive leadership, the longevity of the Chief Executive Officer (CEO) and CFO is tracked from 2012 to 2016. Comparable CDO data is unavailable. $69 \%$ of companies maintain the same CEO, while $44 \%$ of companies maintain the same CFO. Only 23 companies (31\%) have the same CEO and the same CFO in 2012 and 2016. FFG has roughly $20 \%$ higher retention for CEO, CFO and both $\mathrm{CEO} / \mathrm{CFO}$ than $\mathrm{F} 500$. The highest CFO retention is in the industrial $(63 \%)$ and telecom (50\%) industries, and the lowest is the technology industry (27\%). Table 1 provides analytical highlights.

Companies with a reported $\mathrm{CDO}$ average 48 more keywords (30\%) than non-CDO companies. F500 companies with CDOs use $12 \%$ more keywords while FFG companies with CDOs use $58 \%$ more keywords. Although tests calculate weak correlation (0.3) and statistical insignificance, the outcomes suggest that $\mathrm{CDO}$ presence is associated with more frequent signaling of big data initiatives in annual financial reports, especially during periods of high growth.

\section{Discussion}

With the rise of data-based initiatives, three discussion points follow: prominence, prioritization and partnership. Prominence of the keyword "data" is evident in the 8,355 instances, even though the specific phrase "big data" occurs only 45 times overall. While the name may change, big data is here to stay. Every industry is impacted, and executives seek guidance on using it in strategic decision making [9]. According to a New Vantage (NV) survey of Fortune 1000 companies, $63 \%$ of firms are currently using big data [20]. Big data leads to more analytical opportunities.

Prioritization must be given to learning about and integrating big data into predictive analysis and financial decision-making. Despite massive technology investments, many executives are uncertain how to use collected data [9]. Accountable for financial data, CFOs must foster a learning environment and build new capabilities. One survey shows that half of respondents are prioritizing analytical capabilities; successful data capabilities lead to new value creation and improved firm performance [21]. Overall, this requires CFO teams to have a continuous learning mindset. The rate of content generation diminishes response time [17]. CFOs need to get comfortable quickly with big data.

As the $\mathrm{CDO}$ role is increasingly prevalent, partnership between the CFO and CDO is imperative. Of the study sample, $64 \%$ of companies employ a CDO as an executive leader. Similarly, a NV survey reports that firms with a CDO increase 42\% from 2012 to 2016; moreover, $20 \%$ of firms name the CDO as primary owner of big data initiatives [20]. [Note: NV survey includes nine companies captured in this study sample.] Increasing prominence of big data initiatives and data-based decision-making as well as prioritization of analytical capabilities reinforce the need for $\mathrm{CFO}$ and $\mathrm{CDO}$ partnerships. This study suggests, like Ovaska's [22] that tech-savvy finance and accounting teams with data expertise gain competitive advantages $[23,24]$.

\section{Conclusion}

Tech-savvy CFOs with CDO partnerships are best positioned to

\begin{tabular}{|l|c|c|c|c|c|}
\hline Industry & No. of companies & No. of FFG & No. of CDO & Mean (average keywords in 2016) & CFO longevity (same in 2012 and 2016) \\
\hline Consumer & 17 & 1 & 14 & 152 \\
\hline Financial & 16 & 7 & 10 & 181 \\
\hline Health Care & 16 & 8 & 8 & 161 & 367 \\
\hline Technology & 11 & 5 & 7 & 164 & 93 \\
\hline Industrial & 8 & 4 & 4 & 243 \\
\hline Energy & 5 & 0 & 4 & 192 \\
\hline Telecom & 2 & 0 & 1 & 3 \\
\hline TOTAL & 75 & 25 & 48 & 1 \\
\hline
\end{tabular}

Table 1: Frequency distribution. 
Citation: Kralina L (2018) Big Data Signaling in Annual Reports: Does the Presence of a Chief Data Officer (CDO) Signal Big Data Initiatives in Annual Financial Reports? J Bus Fin Aff 7: 331. doi: 10.4172/2167-0234.1000331

harness the complexity and benefits of big data. "Companies tend to get comfortable doing the same thing revolutionary ideas drive the next big growth areas, you need to be a bit uncomfortable to stay relevant." An IBM annual report warns companies not to accommodate big data but to lead it as the world becomes "instrumented, interconnected and intelligent".

The results of this empirical study suggest that CDO presence is associated with more frequent signaling of big data initiatives in annual financial reports. 150 annual reports of top F500 companies and top FFG companies are examined by content analysis using eighteen predetermined keywords. The results show that $64 \%$ of companies employ a $\mathrm{CDO}$ as an executive leader, and companies with CDOs use $30 \%$ more keywords on average than non-CDO firms.

Further studies are needed to assess the extent that big data analyses impact financial decision-making, or conversely, causing 'analysis paralysis' from information overload on finance staff. Additional research is needed to elaborate on keyword associations by conducting in-depth company surveys and interviews and clarifying industry distinctions. Lastly, future research is needed to identify and quantify the efficacy of division of responsibilities for predictive analyses between the $\mathrm{CDO}$ and CFO.

Big data is here to stay. Annual reports are signaling the rise of data-based initiatives. CFOs must embrace the paradigm shift that mandates prominence, prioritization and partnerships of big data.

\section{References}

1. Richards NM, King JH (2014) Big data ethics. Wake Forest Law Review 49 393-432.

2. Megahed $F$, Jones Farmer $L$ (2013) A statistical process monitoring perspective on big data. New York: Springer.

3. Woerner S, Wixom B (2015) Big data: Extending the business strategy toolbox. Journal of Information Technology 30: 60-62

4. Krzanich B (2017) Letter from your CEO, Intel 2016 annual report. Intel.

5. Ansoff IH (1965) The firm of the future. Harvard Business Review.
6. Bauriedel W, Grossman R, Rickards T, Viskin N (2017) Digital transformation The final chapter. Russell Reynolds Associates.

7. Constantiou ID, Kallinikos J (2015) New games, new rules: Big data and the changing context of strategy. Journal of Information Technology 30: 44-57.

8. Porter M (1980) Competitive strategy. The Academy of Management Review.

9. Mazzei M, Noble D (2017) Big data dreams: A framework for corporate strategy. Business Horizons 60: 405-414.

10. Brynjolfsson E, Hitt LM, Kim HH (2011) Strength in numbers: how does datadriven decision-making affect firm performance? SSRN.

11. Davenport T (2014) Big data at work: Dispelling the myths, uncovering the opportunities. Harvard Business Review Press, Boston, MA.

12. Simon HA (1947) Administrative behavior: A Study of Decision-Making Processes in Administrative Organizations. The Free Press.

13. Ross S (1977) The determination of financial structure: The incentive signaling approach. Bell Journal of Economics 8: 23-40.

14. Spence M (1973) Job market signaling. Quarterly Journal of Economics 87 355-374.

15. Campbell D, Shrives P, Saager BH (2001) Voluntary disclosure of mission statements in corporate annual reports: Signaling what and to whom? Business and Society Review 106: 65-87.

16. Srnka AJK, Koeszegi S (2007) From words to numbers: How to transform qualitative data into meaningful quantitative results. Schmalenbach Business Review 1: 29-57.

17. George G, Haas MR, Pentland A (2014) Big data and management. Academy of Management Journal 57: 321-326.

18. Fortune (2017) 2017 Fortune 500. Fortune.

19. Fortune (2017) Fortune 100 fastest growing companies. Fortune.

20. Bean R (2016) Big data executive survey 2016. New Vantage.com

21. LaValle S, Lesser E, Shockley R, Hopkins M, Kruschwitz N (2011) Big data analytics, and the path from insights to value. MIT Sloan Management Review 52: $21-34$

22. Ovaska $F(2017)$ How artificial intelligence is changing accounting. Journal of Accountancy.

23. Page L (2017) G is for Google. Alphabet.com.

24. Rometty V (2017) A letter from the chairman, IBM 2012 annual report. IBM. 